\title{
PENGELOLAAN DANA FILANTROPI UNTUK PEMBERDAYAAN PENDIDIKAN ANAK DHUAFA (Studi Kasus pada BMH Cabang Malang Jawa Timur)
}

\author{
Aan Nasrullah \\ Sekolah Tinggi Agama Islam (STAI) Miftahul 'Ula \\ Jl. KH. Abdul Fatah Ngalwak Kertosono Nganjuk Jawa Timur \\ E-mail: aan.aljalil@ymail.com
}

\begin{abstract}
This study aims to look at how the Institute of Baitul Mal Hidayatullah (BMH) branch Malang manage and distribute philanthropy funds (zakat, infaq, șadaqah and waqf), for the empowerment of poor children education. The approach in this research is qualitative approach, the research design is case study. The results of this study indicate that philanthropy funds have been collected by BMH Branch Malang will be distributed to the four main programs these are, Propagation Program, Education, Social and Economic. The management of philanthropy funds for poor children's education empowerment distributed on three programs: Berpadu (Beasiswa Peduli Anak Dhuafa), PPAS (Pusat Pengembangan Pendidikan Anak Sholeh), and PSD (Pengembangan Sekolah Dhuafa).
\end{abstract}

Abstrak. Penelitian ini bertujuan untuk melihat bagaimana Baitul Mal Hidayatullah (BMH) cabang Malang mengelola dan mendistribusikan dana filantropi (zakat, infaq, șadaqah dan wakaf) untuk pemberdayaan pendidikan anak masyarakat miskin. Pendekatan dalam penelitian ini adalah pendekatan kualitatif dengan desain penelitian studi kasus. Hasil penelitian menunjukkan bahwa dana filantropi yang telah dikumpulkan oleh BMH Cabang Malang akan didistribusikan ke dalam empat program utama, dakwah, pendidikan, sosial dan ekonomi. Pengelolaan dana filantropi untuk pemberdayaan pendidikan anak miskin didistribusikan pada tiga program: Berpadu (Beasiswa Peduli Anak Dhuafa), PPAS (Pusat Pengembangan Pendidikan Anak Sholeh), dan PSD (Pengembangan Sekolah Dhuafa).

Kata Kunci: $\quad$ BMH cabang Malang, Dana filantropi, Pendidikan Anak Dhuafa 


\section{PENDAHULUAN}

Berdasarkan sejumlah data, prestasi pendidikan Indonesia di kancah internasional bisa dikatakan terus merosot dan tertinggal jauh di bawah Negara-Negara Asia lainnya, Salah satunya adalah Indeks Pembangunan Manusia (HDI/Human Develompent Index), berdasarkan data resmi dari UNDP tahun 2004 skor HDI Indonesia 0,697 (skor yang digunakan 0 sampai dengan 1) dan menempati urutan ke 108 dari total 177 negara yang diteliti. ${ }^{1}$ Bahkan dilingkungan Asia Tenggara Indonesia tercecer jauh ketinggalan dari Singapura yang berada pada peringkat ke-25 Dunia yang disusul Brunei Darussalam, Malaysia, Thailand dan Filipina.

Selain HDI indikator lain yang digunakan untuk mengukur tingkat pendidikan suatu Negara adalah indeks pendidikan yang mengabungkan antara indeks melek huruf dewasa dan indeks penduduk dewasa yang mengikuti pendidikan formal, mungkin kita hanya akan mengira bahwa kita akan kalah dari Negara Singapura atau Korea Selatan, ternyata jauh dari itu sejak tahun 2005 kita kalah dari Vietnam dalam soal pendidikan. Indikator lainnya yang lebih relevan dengan kondisi pendidikan secara spesifik adalah nilai hasil belajar, dari data UNDP tahun $2006 \mathrm{kita}$ menempati urutan ke-10 dari 14 Negara Asia Pasifik, Indonesia hanya lebih baik dari Pakistan, Nepal, Papua Nugini dan Solomon.

Dari beberapa indikator kuantitatif di atas mengambarkan bahwa pendidikan nasional saat ini merupakan masalah struktural yang harus segera diselesaikan, jika kondisi pendidikan nasional terus dibiarkan, maka akan berdampak negatif terhadap perekonomian dan bidang sosial lainnya, hal ini karena Indonesia merupakan bagian dari masyarakat dunia yang terbungkus dengan sistem globalisasi yang artinya jika tidak bisa menjadi

${ }^{1}$ Faisal Basri, Catatan Satu Dekade Krisis: Transformasi, Masalah Strukturan dan Harapan Ekonomi Indonesia. (Esensi Erlangga Group: 2009), h. 107 
pemenang, maka pilihan lainya adalah kalah. Hemat penulis bahwa pendidikan merupakan kunci untuk menyiapkan Sumber Daya Manusia (SDM) yang berkualitas, kompetitif serta memiliki keunggulan komparatif, sehingga mampu merebut pangsa pasar tenaga kerja dunia dan pada akhirnya kesejahteraan yang menjadi cita-cita luhur bangsa akan tercapai. Oleh karena itu pendidikan yang berkualitas hendaknya menjadi sebuah keharusan bagi setiap anak bangsa termasuk mereka yang kurang mampu (anak dhu'afa).

Tentu penyelesaian masalah pendidikan nasional bukan semata-mata tanggung jawab pemerintah, namun pihak swasta juga ikut andil di dalamnya. Memang sudah banyak upaya yang dilakukan oleh pemerintah untuk menyelesaikan masalah tersebut, seperti alokasi dana APBN untuk pendidikan sebesar $20 \%$, yang tersalurkan dalam beberapa program sebut saja dana bantuan untuk siswa miskin (BSM/bantuan siswa miskin), dana operasional sekolah (BOS/biaya operasional sekolah) dan program-program lainnya, namun tanpa maksud mengecilkan upaya pemerintah, program-program tersebut dalam pelaksanaannya masih terkesan sebagai "proyek" stake holder pendidikan. Namun hal tersebut bukan menjadi fokus kajian dalam tulisan ini. Penulis akan mengkaji bagaimana peran swasta dalam membantu pemerintah untuk meningkatkan mutu dan kualitas pendidikan nasional.

Penduduk Indonesia yang 85\% adalah masyarakat muslim dan bahkan muslim terbanyak di dunia, maka potensi dana filantropi juga besar yang bisa dimanfaatkan untuk membantu anak dhuafa memperoleh pendidikan yang berkualitas, menurut penelitian Pusat Bahasa dan Budaya UIN Syarif Hidayatullah, potensi dalam bentuk uang tunai kira-kira 14,2 triliun rupiah, dan dalam bentuk barang adalah 5,1 triliun rupiah setiap tahun. Tentu untuk memaksimalkan pengelolaan dan pendistribusian dibutuhkan suatu lembaga sebagai mediator antara mereka yang mampu dan mereka yang berhak menerima. Di Indonesia lembaga 
pengelola dana filantropi yang secara legal diakui oleh pemerintah adalah BAZ (badan amil zakat) dan LAZ (lembaga amil zakat), BAZ adalah lembaga pengelola dana filantropi yang dibentuk oleh pemerintah, sedangkan LAZ adalah lembaga pengelola dana filantropi yang diprakarsai oleh swasta yang mendapatkan izin resmi dari pemerintah. Salah satu LAZ yang konsisten mengelola dana filantropi untuk pendidikan anak dhu'afa adalah Baitul Maal Hidayatullah (BMH) yang sudah memiliki beberapa cabang di beberapa daerah.

Rumusan masalah dalam penelitian ini adalah bagaimana kinerja BMH cabang Malang dalam mengelola dana filantropi (khususnya dana infaq dan wakaf) untuk meningkatkan kualitas pendidikan anak dhu'afa?. Penelitian ini bertujuan untuk mengetahui kinerja BMH cabang Malang dalam pemanfaatan dana filantropi untuk peningkatan kualiatas pendidikan anak dhu'afa. Penelitian ini dibatasi pada LAZ yakni BMH cabang Malang dalam pengelolaan dana filantropi, yakni infak dan wakaf untuk peningkatan kualitas pendidikan khususnya anak dhu'afa yang dirasa kurang mendapatkan pendidikan formal maupun informal.

\section{KAJIAN TEORI}

\section{Filantropi Islam}

Secara estimologi, makna filantropi (philantropy) adalah kedermawanan, kemurahatian, atau sumbangan sosial; sesuatu yang menunjukkan cinta kepada manusia. ${ }^{2}$ Istilah ini berasal dari bahasa Yunani, yaitu philos (cinta) dan antrhopos (manusia), yang secara harfiah bermakna sebagai konseptualisasi dari praktek member (giving), pelayanan (service) dan asosiasi (association)

2John M. Echols dan Hassan Shadly, Kamus Bahasa Inggris. (Jakarta: Gramedia, 1995). 
dengan sukarela untuk membantu pihak lain yang membutuhkan sebagai apresiasi cinta. ${ }^{3}$

Islam sebagai agama yang kāmil dan syāmil serta rahmatan li ál-ālamīn menampilkan dirinya sebagai agama yang berwajah filantropis. Wujud filantropi ini digali dari doktrin keagamaan yang bersumber dari Alquran dan Hadits yang dimodifikasi dengan perantara mekanisme ijtihad sehingga institusi zakat, infaq, sedekah dan wakaf muncul, tujuannya adalah agar harta tersebut tidak hanya berputar pada orang-orang yang memiliki kaya saja, namun juga semua lapisan merasakan putaran uang tersebut. Dalam arti yang lebih luas, perluasan dan percepatan perputaran uang merupakan representasi dari kegiatan ekonomi dan sosial lainnya, oleh karena itu dalam Islam dikenal dua cara dalam pendistribusian harta yakni yang hukumnya wajib dan sunah.

Adapun yang hukumnya wajib adalah zakat dan yang sunah adalah shadaqah, infaq dan wakaf. Jika dilihat berdasarkan sifatnya, dikenal dua bentuk filantropi, yaitu filantropi tradisional dan filantropi untuk keadilan sosial. Filantropi tradisional adalah yang berbasis karitas, praktek filantropi tradisional berbentuk pemberian untuk kepentingan pelayanan sosial, misalkan pemberian langsung para dermawan untuk kalangan miskin dalam rangka memenuhi kebutuhan sehari-hari. Namun kelemahannya adalah tidak bisa mengembangkan taraf kehidupan masyarakat miskin atau dalam istilah sehari-hari hanya memberikan, tapi tidak memberi pancing (kail). Berbeda dengan bentuk filantropi untuk keadilan sosial (social philanthropy justice), bentuk filantropi ini dapat menjembatani jurang pemisah antara si kaya dengan si miskin. Jembatan tersebut diwujudkan dengan upaya memobilisasi sumber daya

\footnotetext{
${ }^{3}$ Chaidier S. Bamualim dan Irfan Abubakar, Revitalisasi Filantropi Islam: Studi Kasus Lembaga Zakat dan Wakaf di Indonesia. Jakarta: Pusat Bahasa dan Budaya, Universitas Islam Negeri Syarif Hidayatullah Jakarta, 1995) dan Ford Foundation.
} 
untuk mendukung kegiatan yang mengugat ketidakadilan struktur yang menjadi penyebab lenggengnya kemiskinan, dengan kata lain, filantropi jenis ini mencari akar permasalahan dari kemiskinan tersebut yakni adanya faktor ketidakadilan dalam alokasi sumber daya dan akses kekuasaan dalam masyarakat. ${ }^{4}$

\section{Pengelola Dana Filantropi}

Untuk memobilisasi dana filantropi agar terkelola secara sistematis dan terstruktur yang kemudian dapat dimanfaatkan sebagaimana mestinya, maka mutlak rasanya diperlukan suatu lembaga yang menjadi mediator antara si kaya dengan si miskin. Dalam perundang-undangan Nomor 38 Tahun 1999, diakui adanya dua jenis organisasi pengelola zakat dan dana filantropi pada umumnya, yaitu: (1) Badan Amil Zakat (BAZ) yaitu organisasi pengelola zakat yang dibentuk oleh pemerintah, dan (2) Lembaga Amil Zakat (LAZ), yaitu Organisasi pengelola zakat yang diprakarsai oleh swasta yang mendapatkan izin resmi dari pemerintah.

Namun dalam UU No. 23 Tahun 2011, terdapat perbedaan organisasi pengelola zakat yang dibentuk oleh masyarakat yang dikukuhkan oleh pemerintah. struktur institusi, dalam upaya untuk mencapai tujuan pengelolaan zakat, dibentuk Badan Amil Zakat Nasional (BAZNAS) yang berkedudukan di ibu kota negara, BAZNAS propinsi, dan BAZNAS kabupaten/kota. BAZNAS merupakan lembaga pemerintahan nonstructural yang bersifat mandiri dan bertanggung jawab kepada Presiden melalui Menteri, BAZNAS merupakan lembaga yang berwenang melakukan tugas pengelolaan zakat dan dana fialntropi lainnya secara nasional.

Untuk membantu BAZNAS dalam pelaksanaan pengumpulan, pendistribusian dan pendayagunaan zakat, masyarakat dapat

${ }^{4}$ Nur Kholis dkk, Potret Filantropi Islam di Propinsi DIY (Jogjakarta: La_Riba Jurnal Ekonomi Islam, . 1995), h. 65 
membentuk Lembaga Amil Zakat (LAZ). Pembentukan LAZ wajib melaporkan secara berkala kepada BAZNAS atas pelaksanaan pengumpulan, pendistribusian, dan pendayagunaan zakat yang telah diaudit syariat dan keuangan, dengan demikian posisi LAZ tidak setara lagi dengan BAZ.

Adapun beberapa LAZ yang telah beroperasi dan memiliki jaringan secara nasional antara lain: Dompet Dhuafa Republika (Jakarta), Amanta Takaful (Jakarta), LAZ Pos Keadilan Peduli Umat (Jakarta), Baitul Maal Muamalat (Jakarta), Dana Sosial Al Falah (Surabaya), Baitul Maal Hidayatullah (Jakarta), Baitul Maal Bank Rakyat Indonesia serta Rumah Zakat Indonesia (Bandung), mayoritas LAZ tersebut mempunyai cabang dikota-kota yang tersebar di tanah air, terkait jumlah anak cabang tentu bervariasi mengikuti besar kecilnya lembaga tersebut. Dalam penelitian ini lembaga pengelola zakat dan dana filantropi pada umumnya yang dimaksud adalah yaitu Baitul Maal Hidayatullah (BMH), lebih tepatnya lagi BMH cabang Malang.

\section{METODE PENELITIAN}

Pendekatan penelitian yang digunakan adalah Pendekatan Kualitatif, pendekatan kualitatif menekankan analisisnya pada proses penyimpulan deduktif dan induktif serta analisis terhadap dinamika hubungan antar fenomena yang diamati, dengan mengunakan logika ilmiah. ${ }^{6}$ Sedangkan jenis atau desain penelitian adalah Studi Kasus, studi kasus bertujuan mempelajari secara intensif latar belakang, status terakhir dan interaksi lingkungan yang terjadi pada satuan sosial seperti individu, kelompok, lembaga atau komunitas. Cakupan Studi Kasus dapat meliputi keseluruhan siklus kehidupan atau dapat pula hanya meliputi segmen-segmen tertentu saja, dapat terpusat pada

\footnotetext{
tt), h. 99-100 2004), h. 5.

${ }^{6}$ Syaifuddin Azwar, Metode Penelitian, (Yogyakarta: Pustaka Pelajar,
}

${ }^{5}$ Sudirman, Zakat dalam Pusaran Arus Modernitas (Malang: UIN Press, 
beberapa faktor yang spesifik dan dapat pula memperhatikan keseluruhan elemen. ${ }^{7}$

Pendekatan Kualitatif dan Jenis Studi Kasus ditujukan untuk mendapatkan gambaran yang komprehensif dan sistematis terkait pengelolaan dana filantropi untuk pemberdayaan pendidikan anak dhuafa oleh BMH Cabang Malang. Sehingga diharapkan dari hasil penelitian dapat diketahui, bagaimana kinerja BMH cabang Malang dalam mengelola dana filantropi (khususnya dana infaq dan wakaf) untuk meningkatkan kualitas pendidikan anak dhu'afa serta problematika apa yang dihadapi.

Sumber data dalam penelitian ini terbagi menjadi data primer dan sekunder, data primer dalam penelitian ini adalah data yang langsung diperoleh dari informan berdasarkan wawancara, informan dalam penelitian ini adalah orang-orang yang berada dalam struktur kepengurusan BMH Cabang Malang, diantarannya: Abdullah Warsito (Kepala Cabang BMH Cabang Malang), Abu Fadhilah (Kepala Devisi Keuangan), Human Hidayat (Kepada Devisi Pendayagunaan), Imron Mahmudi (Staff Administrasi) dan Abdul Jamil (Koordinator Desa Binaan). Sedangkan data Sekunder dalam penelitian ini adalah data-data terkait dengan penelitian, seperti data keuangan BMH Cabang Malang, data Donatur tetap, data Anak Asuh dll. Serta catatancatatan terkait dengan BMH Cabang Malang, seperti Majalah terbitan BMH Pusat dan cabang Malang, hasil penelitian sebelumnya.

Untuk mendapatkan data yang sesuai yang dengan kebutuhan penelitian serta agar data yang diperoleh dapat dipertanggungjawabkan dan dapat diuji kevaliditasannya, maka teknik pengumpulan data dalam penelitian ini mengunkan tiga teknik pengumpulan data, yaitu Observasi, Wawancara Mendalam (depth interview) dan Studi Dokumentasi.

${ }^{7}$ Ibid., h. 8 
Dalam penelitian ini analisis data yang digunakan adalah analisis kualitatif deskriptif yaitu dengan cara memaparkan informasi-informasi faktual yang diperoleh dari BMH cabang Malang, yang berhubungan dengan pengelolaan dana filantropi mulai dari penghimpunan sampai dengan pemanfatan dana tersebut untuk kepentingan pendidikan anak dhuafa, dengan tujuan membuat deskripsi, gambaran atau lukisan secara sistematis, faktual dan akurat mengenai fakta-fakta, sifat-sifat serta fenomena yang diteliti. ${ }^{8}$

\section{HASIL DAN PEMBAHASAN}

\section{Sekilas Tentang BMH Cabang Malang}

Secara Nasional Baitul Maal Hidayatullah (BMH) berkantor pusat di Jakarta, sejak tahun 2001 telah membuka beberapa cabang di beberapa daerah salah satunya berada di Malang Jawa Timur. BMH cabang Malang berkantor di JL. Raya Sidomakmur No. 45 Sengkaleng Dau Malang. Dalam kiprahnya BMH cabang Malang menghimpun dana filantropi berupa Zakat, Infaq, Wakaf, Hibah dll yang berasal dari masyarakat baik pemerintah, BUMN, maupun swasata. Dana filantropi yang telah terkumpul kemudian akan disalurkan kepada mereka yang berhak sesuai dengan program-program yang telah dicanangkan tentu berdasarkan kebutuhan si penerima'.

\section{Pendayagunaan Dana Filantropi untuk Pendidikan Anak Dhuafa}

Pada dasarnya dana filantropi yang telah mampu di kumpulkan oleh BMH Cabang Malang akan didistribusikan ke berbagai bidang utama, yakni bidang Dakwah, Pendidikan, Sosial dan Ekonomi, namun agar penelitian ini tidak melebar dan mampu memberikan hasil yang informatif, maka penelitian ini difokuskan pada bidang pendidikan, yakni bagaimana manajemen dana filantropi untuk

\footnotetext{
${ }^{8}$ Moh. Nazir, Metode Penelitian, (Jakarta: PT Ghalia Indonesia, 2003)

${ }^{9}$ Hasil wawancara dengan Imron Mahmudi, Staff Administrasi BMH Cabang Malang, Tanggal 23 Maret 2010
} 
pemberdayaan pendidikan anak dhuafa. Adapun pengelolaan dana filantropi untuk pemberdayaan pendidikan anak dhuafa disalurkan pada tiga program utama, yaitu: Berpadu (Beasiswa Peduli Anak Dhuafa), PPAS (Pusat Pengembangan Pendidikan Anak Sholeh), dan PSD (Pengembangan Sekolah Dhuafa).

\section{Berpadu (Beasiswa Peduli Anak Dhuafa)}

Program ini memberikan beasiswa pendidikan kepada anak dhuafa dan anak Yatim yang orang tuanya tidak mampu membayar administrasi sekolah, dengan menjadikan anak dhuafa atau anak yatim tersebut sebagai Anak Asuh BMH Cabang Malang, maka anak asuh tersebut akan secara rutin pada setiap bulannya menerima beasiswa pendidikan dari BMH cabang Malang. Untuk program Berpadu ada dua jenis program, yakni beasiswa berkah (non asrama) dan beasiswa kader (asrama). Beasiswa Berkah adalah beasiswa yang diberikan kepada anak asuh BMH Cabang Malang yang bertempat tinggal jauh dari lokasi BMH Cabang Malang. Sedangkan beasiswa kader adalah beasiswa yang diberikan kepada anak asuh yang tinggal di Pondok Pesantren Hidayatullah (ponpes dibawah naungan BMH Cabang Malang) baik putra maupun putri.

Adapun kriteria untuk menjadi anak asuh BMH cabang Malang adalah sebagai berikut:

- Anak Yatim/anak dhuafa

- Masih Sekolah

- Surat Keterangan tidak mampu dari RT setempat

- Mengikuti peraturan yang telah ditetapkan oleh BMH Cabang Malang, seperti tidak merokok dan mengikuti kegiatan keagamaan yang diadakan oleh BMH Cabang Malang, dan

- Tidak harus anak pandai, karena salah satu tujuan dari program berpadu adalah pemberdayaan pendidikan anak dhuafa. 
Mekanisme pemberian dana beasiswa khususnya beasiswa berkah, tidak diberikan secara langsung kepada anak asuh, melainkan melalui koordinator lapangan. ${ }^{10}$ Koornidator lapangan adalah 'Āmil yang tinggal dan mempunyai tanggung jawab penuh atas anak asuh yang bertempat di desa binaan. Tugas dan tanggung jawab koordinator lapangan adalah mengajukan permohonan kepada BMH Cabang Malang calon anak asuh, menyalurkan beasiswa dari BMH Cabang Malang kepada anak asuh dan membuat laporan keuangan dan perkembangan anak asuh kepada BMH Cabang Malang. Keberadaan koordinator lapangan, memudahkan BMH Cabang Malang dalam pengelolaan dana filantropi untuk pemberdayaan anak dhuafa, mulai dari penjaringan calon anak asuh sampai pada pendistribusian dana beasiswa.

Data kuantitatif menunjukkan sampai akhir 2009 anak asuh BMH Cabang Malang telah mencapai 550 anak asuh yang tersebar di 25 desa binaan. Jumlah anak asuh BMH Cabang Malang dari tahun ke tahun selalu mengalami peningkatan, adapun jumlah anak asuh dan serta dana yang telah tersalurkan untuk program berpadu berkah adalah sebagai berikut:

Tabel 1

Perkembangan anak asuh dan dana beasiswa

\begin{tabular}{cccc}
\hline No & Tahun & Jumlah Anak Asuh & Dana yang telah tersalurkan (Rp) \\
\hline 1 & 2004 & 225 & 34.850 .000 \\
\hline 2 & 2005 & 300 & 38.023 .000 \\
\hline 3 & 2006 & 350 & 60.700 .000 \\
\hline 4 & 2007 & 425 & 93.972 .000 \\
\hline 5 & 2008 & 494 & 128.898 .000 \\
\hline 6 & 2009 & 550 & 166.290 .000 \\
\hline & Total & $\mathbf{1 . 7 9 4}$ & $\mathbf{3 5 6 . 4 4 3 . 0 0 0}$ \\
\hline
\end{tabular}

Sumber: Laporan tahunan BMH Cabang Malang

${ }^{10}$ Hasil wawancara dengan Abdul Jamil, koordinator desa binaan Kucur Dau Malang, tanggal 13 April 2010. 
Data di atas menunjukkan jumlah anak asuh BMH Cabang Malang selalu bertambah hingga 70 anak asuh setiap tahunnya, bertambahnya jumlah anak asuh, maka bertambah pula dana beasiswa yang dikeluarkan oleh BMH Cabang Malang sebagaimana yang tersaji pada tabel 4.1 di atas. Mengenai penyebaran anak asuh berdasarkan desa binanaan dan jenjang pendidikan tersaji pada tabel 4.2 berikut:

Tabel 2

Penyebaran Anak Asuh Berdasarkan Desa Binaan dan Jenjang Pendidikan

\begin{tabular}{|c|c|c|c|c|c|c|}
\hline \multirow{2}{*}{ No } & \multirow{2}{*}{ Desa Binaan } & \multirow{2}{*}{ Koordinator } & \multicolumn{4}{|c|}{ Jumlah anak asuh } \\
\hline & & & SD & SLTP & SLTA & Total \\
\hline 1 & Sumberejo - Kota Batu & $\begin{array}{l}\text { Abdul } \\
\text { Hamid }\end{array}$ & 26 & 15 & 0 & 41 \\
\hline 2 & Bumiaji - Kota Batu & Aguk & 20 & 1 & 0 & 21 \\
\hline 3 & Dadaprejo - Kota Batu & Kartini & 10 & 0 & 0 & 10 \\
\hline 4 & Sengkaling - Dau Malang & Khamaliyah & 4 & 0 & 1 & 5 \\
\hline 5 & Jetak - Dau Malang & Suwoto & 18 & 0 & 0 & 18 \\
\hline 6 & Kucur - Dau Malang & $\begin{array}{l}\text { Abdul } \\
\text { Hamid }\end{array}$ & 20 & 8 & 0 & 28 \\
\hline 7 & $\begin{array}{l}\text { Sumberbendo-Dau } \\
\text { Malang }\end{array}$ & Ali Sujarno & 19 & 1 & 0 & 20 \\
\hline 8 & Kasikon - Pakisaji Malang & Kholifah & 36 & 0 & 0 & 36 \\
\hline 9 & $\begin{array}{l}\text { Putukrejo - Pakisaji } \\
\text { Malang }\end{array}$ & Subiyanto & 32 & 0 & 0 & 32 \\
\hline 10 & $\begin{array}{l}\text { Penarukan - Kepanjen } \\
\text { Malang }\end{array}$ & Subanjar & 18 & 3 & 0 & 21 \\
\hline 11 & $\begin{array}{l}\text { Arjowilangun - Kalipare } \\
\text { Malang }\end{array}$ & Darul Qutni & 15 & 4 & 0 & 19 \\
\hline 12 & Donomulyo - Malang & A. Yani & 18 & 4 & 2 & 24 \\
\hline 13 & $\begin{array}{l}\text { Sumberoto - Donomulyo } \\
\text { Malang }\end{array}$ & $\begin{array}{l}\text { Joko } \\
\text { Suwikto }\end{array}$ & 28 & 1 & 1 & 30 \\
\hline 14 & $\begin{array}{l}\text { Sumbermanjing kulon - } \\
\text { Pagak Malang }\end{array}$ & Sukriono & 14 & 6 & 0 & 20 \\
\hline 15 & $\begin{array}{l}\text { Sendangbiru - } \\
\text { Sumbermanjing wetan } \\
\text { Malang }\end{array}$ & $\begin{array}{l}\text { Eko } \\
\text { Wahyudi }\end{array}$ & 28 & 0 & 0 & 28 \\
\hline 16 & $\begin{array}{l}\text { Kebonsari - Tumpang } \\
\text { Malang }\end{array}$ & $\begin{array}{l}\text { Syamsul } \\
\text { Hadi }\end{array}$ & 47 & 13 & 2 & 62 \\
\hline 17 & $\begin{array}{l}\text { Malangsuko - Tumpang } \\
\text { Malang }\end{array}$ & Muhartono & 15 & 0 & 0 & 15 \\
\hline
\end{tabular}


Aan Nasrullah, Pengelolaan Dana Filantropi...

\begin{tabular}{lllcccc}
\hline \multirow{2}{*}{ No } & \multirow{2}{*}{ Desa Binaan } & \multirow{2}{*}{ Koordinator } & \multicolumn{5}{c}{ Jumlah anak asuh } \\
\cline { 4 - 7 } & & SD & SLTP & SLTA & Total \\
\hline 18 & Ciliwung - Kota Malang & Sri W & 0 & 10 & 0 & 10 \\
\hline 19 & Tulusrejo - Kota Malang & Agus & 10 & 0 & 0 & 10 \\
\hline 20 & PPAS & Arifin & 1 & 3 & 9 & 13 \\
\hline 21 & Kasembon & M. Haidar & 16 & 0 & 0 & 16 \\
\hline 22 & $\begin{array}{l}\text { Pandansari - } \\
\text { Poncokusumo }\end{array}$ & Muktamar & 10 & 0 & 0 & 10 \\
\hline 23 & Klojen - Kota Malang & Warti & 1 & 2 & 2 & 5 \\
\hline 24 & $\begin{array}{l}\text { Karanganyar - } \\
\text { Poncokusumo }\end{array}$ & Ali Muji & 10 & 2 & 1 & 13 \\
\hline 25 & Blayu - Wajak & Aqif K & 17 & 3 & 0 & 20 \\
\hline Jumlah Jenjang Pendidikan & & $\mathbf{4 3 3}$ & $\mathbf{7 6}$ & $\mathbf{1 8}$ & $\mathbf{5 2 7}$ \\
\hline Sumber : laporan penyebaran anak asuh diolah oleh peneliti & &
\end{tabular}

Data di atas menunjukkan bahwa lokasi desa binaan sebagian besar berada diwilayah Malang pinggiran, seperti Desa Kucur Dau Malang yang berjarak 46km dari kota Malang. Sampai akhir 2009 desa binaan dengan jumlah anak asuh terbanyak berada di desa Kebonsari Tumpang Malang dengan koordinator Syamsul Hadi dengan 62 anak asuh, sedangkan yang paling sedikit adalah kelurahan Klojen Malang 5 anak asuh dengan koordinator Warti. Dilihat dari jenjang pendidikan, maka porsi paling besar berada pada jenjang Sekolah Dasar (SD) dengan jumlah 433 anak asuh, disusul Sekolah Menengah Pertama (SMP) dengan jumlah 76 anak asuh dan Sekolah Menengah Atas (SMA) dengan jumlah 18 anak asuh.

Nominal beasiswa yang diberikan kepada anak asuh bervariasi sesuai dengan jenjang pendidikan, untuk jenjang SD mendapat beasiswa sebesar Rp. 30.000/bln (Rp. 420.000/th), untuk anak asuh jenjang SMP mendapat beasiswa sebesar Rp. 45.000/bln (Rp. 540.000/th), sedangkan untuk jenjang SMA mendapat beasiswa sebesar Rp. 55.000/bln (Rp. 660.000/th). Nominal yang berbeda-beda untuk setiap jenjang pendidikan, karena kebutuhan atau biaya pendidikan juga berbeda, di mana kebutuhan biaya pendidikan jenjang SMA lebih besar dari pada kebutuhan pendidikan jenjang SD dan SMP. Pemberian beasiswa kepada anak 
dhuafa dengan menjadikan anak asuh diharapkan anak dhuafa yang tidak mampu sekolah karena alasan keterbatasan biaya sekolah dapat teratasi.

\section{PPAS (Pusat Pengembangan Pendidikan Anak Sholeh)}

Program kedua dalam pendayagunaan dana filantropi adalah program Pusat Pengembangan Pendidikan Anak Sholeh (PPAS), PPAS adalah upaya BMH cabang Malang dalam rangka menyiapkan kader-kader professional dan berkompeten. BMH cabang Malang mendirikan dua pondok pesantren (Pon-Pes), yakni Pon-Pes Hidayatullah Putra dan Putri kedua Pon-Pes ini berada di bawah naungan Lembaga Pendidikan Islam Ar-Rahmah. Dengan pemusatan pendidikan di Pon-Pes ini diharapkan pendidikan yang diterima anak asuh baik pendidikan agama maupun ketrampilan bisa diserap oleh anak asuh secara maksimal.

Sebagaimana hasil wawancara dengan peneliti dengan Abu Fadilah Kepala Devisi Keuangan, bahwa sistem pembinaan (kurikulum) santri (anak asuh) Pon-Pes Hidayatullah adalah Sistem Nuzulul Wahyu (SNW) yang diintegrasikan dengan KTSP (kurikulum tingkat satuan pendidikan), dengan sistem ini para anak asuh dikuatkan aqidahnya, salah satunya dengan membiasakan anak asuh dengan qiyāmul lail, disamping itu pemberian keterampilan dirasa mutlak untuk diberikan kepada anak asuh, terutama untuk bekal para anak asuh setelah lulus dari Pon-Pes Hidayatullah.

Untuk pendidikan formal di Pon-Pes Hidayatullah Putri, meliputi Play Group, SD Alam Ar-Rohmah dan SMP Ar-Rohmah, sedangkan di Pon-Pes Hidyatullah Putra meliputi SMP Ar-Rohmah dan SMA Ar-Rohmah. Pemberian pendidikan agama dan keterampilan merupakan upaya dari BMH cabang Malang melalui Lembaga Pendidikan Islam Ar-Rohmah untuk menjadikan anak asuh menjadi pribadi-pribadi yang unggul yang menjadi 
kebanggaan umat, serta diharapkan dari PPAS ini akan lahir generasi terbaik yang akan membawa kejayaan Islam.

Dari segi kuantitas anak asuh memang mengalami pasang surut, di mana pada tahun 2004 anak asuh yang berada di Pon-Pes Hidayatullah berjumlah 80 santri dan pada tahun 2009 berjmulah 55 santri, namun upaya untuk BMH Cabang Malang untuk meningkatkan kualitas anak asuh tidak pernah berhenti, hal ini bisa dilihat meski secara kuantitas mengalami penurunan, namun untuk meningkatkan kualitas pendidikan anak asuh, dana yang dikucurkan oleh BMH cabang Malang tidak berpatok pada jumlah anak asuh, hal ini bisa dilihat dari tabel 4.3 berikut:

Tabel 3

Rekap Penyaluran Beasiswa Kader Pon-Pes Hidayatullah Malang

\begin{tabular}{cccc}
\hline No & Tahun & Jumlah Penerima (Anak Asuh) & Nominal (Rp) \\
\hline 1 & 2004 & 80 & 53.350 .000 \\
\hline 2 & 2005 & 60 & 48.350 .000 \\
\hline 3 & 2006 & 40 & 93.609 .500 \\
\hline 4 & 2007 & 30 & 74.315 .000 \\
\hline 5 & 2008 & 21 & 145.056 .000 \\
\hline 6 & 2009 & 55 & 131.208 .000 \\
\hline
\end{tabular}

Sumber: laporan Keuangan BMH cabang Malang, 2009

Besaran nominal beasiswa kader yang kucurkan oleh BMH cabang Malang, kepada anak asuh melalui Pon-Pes Hidayatullah diharapkan dapat mejamin bahwa anak asuh yang mendapat beasiswa kader akan mendapat pendidikan yang berkualitas.

\section{PSD (Pengembangan Sekolah Dhuafa)}

PSD adalah program bantuan tenaga pendidik kepada sekolah yang membutuhkan/kekurangan tenaga pendidik. Dengan cara mengirimkan seorang tenaga pendidik atau trainer ke sekolah-sekolah yang memang memerlukan bantuan tenaga pendidik, biasanya adalah sekolah-sekolah yang berada di daerah pinggiran Malang Raya. 
Tujuan dari program ini antara lain adalah meningkatkan kualitas pendidikan anak dhuafa melalui peningkatan kualitas tenaga pengajar. Hal ini menginggat, karena salah satu faktor fundamental keberhasilan pendidikan terletak pada kualitas tenaga pendidik atau pengajar. Oleh karena itu BMH cabang Malang senantiasa meningkatkan baik kuantitas maupun kualitas Trainer yang dikirim ke sekolah-sekolah wilayah Malang Raya. Tidak banyak data dan informasi yang peneliti peroleh dari BMH cabang Malang terkait dengan Program PSD, sekiranya kekurangan data dan informasi ini dapat dilengkapi oleh penelitipeneliti yang akan datang.

Sedangkan untuk sumber dan penyaluran dana filantropi dalam program pendidikan oleh $\mathrm{BMH}$ cabang Malang dapat dilihat dari gambar berikut:

Skema Sumber dan Penyaluran Dana Filantropi untuk Program Pendidikan

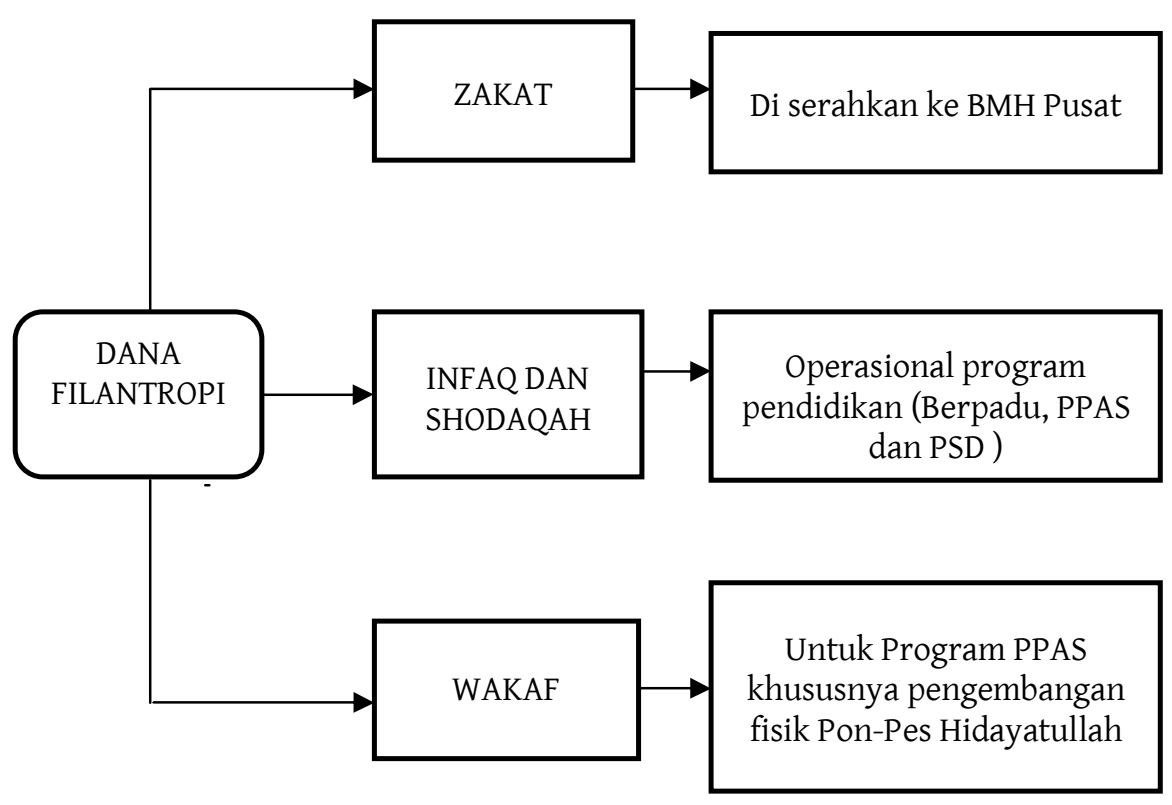




\section{PENUTUP}

Dari pemaparan hasil dan pembahasan penelitian di atas, maka manajemen dana filantropi yang telah diterapkan oleh BMH cabang Malang untuk meningkatkan kualitas pendidikan anak dhuafa disalurkan dalam tiga program pendidikan, yakni program Berpadu, Pusat Pengembangan Pendidikan Anak Sholeh dan Pengembangan Sekolah Dhuafa.

Pertama, Berpadu (Beasiswa Peduli Anak Dhuafa, program ini memberikan beasiswa pendidikan kepada anak dhuafa dan anak Yatim yang orang tuanya tidak mampu membayar administrasi sekolah, dengan menjadikan anak dhuafa atau anak yatim tersebut sebagai Anak Asuh BMH Cabang Malang, maka anak asuh tersebut akan secara rutin pada setiap bulannya menerima beasiswa pendidikan dari BMH cabang Malang. Untuk program Berpadu ada dua jenis program, yakni beasiswa berkah (non asrama) dan beasiswa kader (asrama).

Kedua, Pusat Pengembangan Pendidikan Anak Sholeh (PPAS), merupakan program BMH cabang Malang dalam rangka menyiapkan kader-kader professional dan berkompeten. Dengan cara mendirikan dua pondok pesantren (Pon-Pes), yakni Pon-Pes Hidayatullah Putra dan Putri kedua Pon-Pes ini berada di bawah naungan Lembaga Pendidikan Islam Ar-Rahmah. Dengan pemusatan pendidikan di Pon-Pes ini diharapkan pendidikan yang diterima anak asuh baik pendidikan agama maupun ketrampilan bisa diserap oleh anak asuh secara maksimal.

Ketiga, Pengembangan Sekolah Dhuafa (PSD), adalah program bantuan tenaga pendidik kepada sekolah yang membutuhkan/kekurangan tenaga pendidik. Dengan cara mengirimkan seorang tenaga pendidik atau trainer ke sekolahsekolah yang memang memerlukan bantuan tenaga pendidik, biasanya adalah sekolah-sekolah yang berada di daerah pinggiran Malang Raya, dengan tujuan meningkatkan kualitas pendidikan anak dhuafa melalui peningkatan kualitas tenaga pengajar. 


\section{DAFTAR PUSTAKA}

Asnaini, "Membangun Zakat Sebagai Upaya Membangun Masyarakat" dalam La_Riba: Jurnal Ekonomi Islam, Vol. IV, No. 1, (Juli 2010).

Anshori, Abdul Ghofur. Hukum dan Praktek Perwakafan di Indonesia, Yogyakarta: Pilar Media, 2006.

Arikunto, Suharsini. Prosedur Penelitian Suatu Pendekatan Praktek, Jakarta: Rineka Cipta, 2006.

Azwar, Syaifuddin. Metode Penelitian, Yogyakarta: Pustaka Pelajar, 2004.

Basri , Faisal. Catatan Satu Dekade Krisis: Transformasi, Masalah Strukturan dan Harapan Ekonomi Indonesia, Jakarta: Esensi Erlangga Group, 2009.

Chaidier S. Bamualim dan Irfan Abubakar. Revitalisasi Filantropi Islam: Studi Kasus Lembaga Zakat dan Wakaf di Indonesia. Jakarta: Pusat Bahasa dan Budaya, Universitas Islam Negeri Syarif Hidayatullah Jakarta dan Ford Foundation, 2005.

John M. Echols dan Hassan Shadly. Kamus Bahasa Inggris. Jakarta: Gramedia, 1995.

Moloeng, Lexy J. Metodologi Penelitian Kualitatif. Bandung: Remaja Rosda Karya, 2005.

Nazir, Mohammad. Metode Penelitian. Jakarta: PT Ghalia Indonesia, 2003.

Nur Kholis dkk. Potret Filantropi Islam di Propinsi DIY. Yogjakarta: La_Riba Jurnal Ekonomi Islam Vol. VII, No. 1 Juli 2013.

Qardawy, Yusuf. Hukum Zakat Studi Komparatif Mengenai Status and Filsafat Zakat berdasarkan Qur'an dan Hadits. Bandung: Pustaka Litera Antar Nusa, 1996.

Sudirman, Zakat dalam Pusaran Arus Modernitas. Malang: UIN Press, t.th. 